\title{
Evaluación de películas comestibles de almidón de yuca y proteína aislada de soya en la conservación de fresas
}

\author{
Nataly Saavedra $\mathrm{H}^{1}$, Néstor A. Algecira $\mathrm{E}^{2}$ \\ 1. Departamento de Química. Universidad Nacional de Colombia \\ 2. Departamento de Ingeniería Química y Ambiental. Universidad Nacional de Colombia \\ Correspondencia: nsaavedrah@unal.edu.co
}

Recibido: 27-07-10/Aceptado: 4-11-10

\begin{abstract}
Resumen
A partir de diferentes proporciones de almidón de yuca y proteína aislada de soya, se elaboraron películas comestibles por el método de casting, las cuales se caracterizaron a través de pruebas mecánicas, térmicas y morfológicas. Se evaluó el desempeño de las películas como recubrimiento sobre las fresas variedad ventana mediante la determinación de propiedades sensoriales y fisicoquímicas: color, apariencia, aroma, sabor, textura, $\mathrm{pH}$, acidez titulable y sólidos solubles totales a temperaturas ambiente y de refrigeración. En las formulaciones que contenían proteína se observó una mayor elasticidad, eventos térmicos a temperatura más baja comparados con los de las mezclas, una superficie más homogénea, permitiendo mejorar algunas propiedades del fruto durante su almacenamiento como la pérdida de peso. Las propiedades sensoriales se evaluaron utilizando las pruebas de Kruskal Wallis y Friedman, obteniendo en la primera diferencias no significativas ( $p>0.05)$ entre los tratamientos evaluados y diferencias significativas en la segunda, observando un desempeño favorable en los recubrimientos comestibles.
\end{abstract}

Palabras clave: películas comestibles, almidón de yuca, proteína aislada de soya, fresas.

\section{Abstract \\ Evaluation of edible films of cassava starch and isolated soy protein in the preservation of strawberries}

Made from different proportions of cassava starch and isolated soybean protein, edible films were prepared by the casting method, which is characterized by mechanical, thermal and morphological tests. The performance of the films was assessed as a coating on the ventana variety strawberries by determining sensory and physicochemical properties as color, appearance, aroma, flavor, texture, $\mathrm{pH}$, acidity and total soluble solids storage at two temperatures: ambient and cooling. In the formulations containing protein a higher elasticity, thermal events at a lower temperature compared with the mixtures, a more homogeneous surface, allowing to improve some properties of the fruit during storage and 
weight loss. The sensory properties were evaluated using Kruskal Wallis and Friedman tests obtaining no significant differences $(p>0.05)$ in the first test between treatments and, for the second, significant differences, having a favorable performance in edible coatings.

Keywords: cassava starch, edible films, edible coating, isolated soy protein, strawberries.

\section{Introducción}

Los recubrimientos comestibles se definen como productos comestibles que forman una fina capa sobre el alimento y se caracterizan por (1); constituyen una barrera semipermeable a los gases y al vapor de agua que retrasa el deterioro del alimento, mejoran las propiedades mecánicas, ayudan a mantener la integridad estructural del producto que envuelven, a retener compuestos volátiles y pueden actuar como vehículo de aditivos alimentarios (2). Aplicados a las frutas permiten controlar la respiración y la senescencia de forma similar a las atmósferas modificadas, ejerciendo así una barrera a los gases y al vapor de agua. De esta manera se reduce el deterioro del fruto (3).

Los principales componentes de los recubrimientos comestibles son polisacáridos, proteínas, lípidos $\mathrm{y}$ resinas (4-6). Las formulaciones pueden incluir, además, plastificantes y emulsificantes de distinta naturaleza química con el fin de mejorar las propiedades de los recubrimientos. Los polisacáridos y las proteínas son polímeros que forman redes moleculares cohesionadas por una alta interacción entre sus moléculas, estos les confiere buenas propiedades mecánicas y de barrera a gases $\left(\mathrm{O}_{2} \mathrm{y} \mathrm{CO}_{2}\right)$ (7). Por su naturaleza hidrofóbica los lípidos ejercen una buena barrera al vapor de agua, sin embargo, su falta de cohesividad e integridad estructural hace que presenten malas propiedades mecánicas formando recubrimientos quebradizos. La incorporación de plastificantes tiene como objetivo mejorar la flexibilidad de los recubrimientos, haciéndolos menos frágiles; la de los emulsificantes favorecer la dispersión del lípido en la matriz hidrocoloide, mejorado la capacidad del recubrimiento para impregnar al alimento y formar una capa continua en la superficie del mismo $(1,8)$.

En la elaboración de películas comestibles se emplean mezclas entre biopolímeros con el fin de contrarrestar las deficiencias propias de cada componente y así poder mejorar las propiedades del material resultante (9-11). Almidones de diferentes fuentes como trigo, maíz, papa y yuca se han utilizado, obteniendo, con este último, películas con buenas propiedades de flexibilidad y permeabilidad al vapor de agua (12). Las proteínas de soya han sido estudiadas por su excelente capacidad para formar películas y por sus buenas propiedades de barrera a lípidos y oxígeno en humedades relativamente bajas (13-15).

Por otra parte, las fresas son frutas con una alta tasa de respiración muy dependiente de la temperatura, del tiempo de almacenamiento y estado de maduración. Por tratarse de un producto perecedero, su calidad y vida útil pueden verse mejoradas por el control de los procesos de deterioro e inactivación de procesos fisiológicos, tanto del propio fruto como de los patógenos que pueda contener $(16,17)$.

Entre algunos de los materiales que se han empleado en la elaboración de recubrimientos para fresas se encuentra el gluten de trigo, cera de abejas, carragenina, almidón, quitosano, metilcelulosa y gelatina. Se han obtenido resultados benéficos en las propiedades fisicoquímicas al utilizar estos materiales, por ejemplo el gluten de trigo junto con cera de abejas permitió conservar la firmeza, reducir la pérdida de peso y procesos de senescencia del fruto (2). Al utilizar quitosano como material hidrocoloide con la adición de calcio y vitamina $\mathrm{E}$ se observó un retraso en el cambio del color, $\mathrm{pH}$ y acidez titulable así como un aumento en el contenido de estos nutrientes en frutos 
frescos y congelados (17), el uso de recubrimientos de carragenina enriquecidos con calcio produjo una menor pérdida de firmeza en los frutos evaluados (4).

El objetivo del presente trabajo fue elaborar y evaluar películas comestibles a partir de proteína aislada de soya y almidón de yuca en mezcla de diferentes proporciones para determinar la mejor opción por sus propiedades fisicoquímicas y sensoriales para la conservación y aumento de vida útil de fresas frescas.

\section{Materiales y métodos}

Los materiales empleados en la elaboración de las películas fueron: agua, almidón de yuca comercial (donado por Corn Products Andina), proteína aislada de soya, aceite de canola comercial, glicerol, Tween 60 (monoestearato de sorbitan etoxilado). Se emplearon fresas de la variedad ventana cortadas del día anterior proveniente de un mismo cultivo localizado en el municipio de Guasca-Cundinamarca en un estado de madurez del 75\%.

Preparación de las películas: se elaboraron diferentes tipos de películas manteniendo la composición de $2 \mathrm{~g}$ de material hidrocoloide (almidón y proteína), $2 \mathrm{~g}$ glicerol, $0.4 \mathrm{~g}$ Aceite y $0.4 \mathrm{~g}$ Tween 60 por cada $100 \mathrm{~g}$ de solución (18).

Película de almidón: el total de agua a utilizar se dividió en tres fracciones: en la primera se dispersó el almidón de yuca que se llevó a calentamiento hasta su gelatinización, mientras se mantuvo en agitación constante. En la segunda fracción, se adicionó la cantidad de glicerol que posteriormente se incorporó gota a gota al gel de almidón ya formado. Estos componentes se dejaron en agitación constante durante 10 minutos. Posterior a esto se adicionó gota a gota la tercera porción de agua en la que previamente se había incorporado el emulsificante (Tween 60) y el aceite de canola con el fin de formar la emulsión. Finalmente se dejó el sistema en agitación constante por 30 minutos.

Película de proteína: se empleó un procedimiento similar al descrito en la película de almidón, con la diferencia que el agua a utilizar se llevó a pH 10 empleando una solución de hidróxido de sodio.

Película de almidón y proteína (50:50): se realizó por separado la disolución del almidón y de la proteína. Cuando el almidón se encontraba gelatinizado se procedió adicionar gota a gota la proteína ya disuelta en una cantidad de agua a pH 10. Se dejó en agitación constante durante un tiempo aproximado de 10 minutos para luego adicionar gota a gota la fracción de glicerol y seguir con el procedimiento descrito en las formulaciones anteriores. Una vez obtenida la suspensión filmogénica se vertió sobre un molde recubierto con teflón de $15 \mathrm{~cm} \times 15 \mathrm{~cm}$, la cual fue llevada a una cabina de secado durante 48 horas a una temperatura de $40^{\circ} \mathrm{C}$. Una vez formada la película seca se desmoldó y se realizaron las caracterizaciones térmicas, mecánicas y morfológicas.

Acondicionamiento de la fruta: después de seleccionadas las fresas se sometieron inicialmente a un lavado con agua, seguido de un proceso de desinfección con una solución de hipoclorito de sodio en agua a $60 \mathrm{ppm}$. Luego se realizó un nuevo lavado con agua para retirar los restos de hipoclorito y se finalizó con el secado de la fruta.

Aplicación del recubrimiento y almacenamiento: la aplicación del recubrimiento se realizó por inmersión de la fresa en la suspensión filmogénica durante 1 minuto. Después se colocaron las fresas en moldes permitiendo el secado del recubrimiento. Al siguiente día se procedió a separar cada una de las formulaciones empleadas en dos grupos de estudio. a. Temperatura 1 a $18^{\circ} \mathrm{C}, \mathrm{b}$. Temperatura 2 a $7^{\circ} \mathrm{C}$, comparados siempre con las fresa patrón (fresas sin recubrimiento) con lo cual se tuvieron 4 tratamientos para cada una de las temperaturas, es decir 8 lotes de estudio.

\section{Caracterización de las películas}

Medidas de tensión: se utilizó un texturómetro TATX PLUS (A/TG; Tensile Grips) con una velocidad antes, durante y después de la prueba de $1 \mathrm{~mm} / \mathrm{s}, 1$ $\mathrm{mm} / \mathrm{s}$ y $10 \mathrm{~mm} / \mathrm{s}$ respectivamente y una distancia de elongación de $25 \mathrm{~mm}$. Los especímenes de películas a 
utilizar fueron de $1.5 \mathrm{~cm}$ de ancho por $6 \mathrm{~cm}$ de largo.

Calorimetría diferencial de barrido (MDSC): los ensayos de DSC modulado se llevaron a cabo en un TA Instruments DSC 2910 empleando una rampa desde $-60^{\circ} \mathrm{C}$ hasta $150^{\circ} \mathrm{C}$ a una velocidad de calentamiento de $5^{\circ} \mathrm{C} / \mathrm{min}$ con una modulación de $1 \%$ minuto en atmósfera inerte con inyección de $\mathrm{N}_{2}$ a una velocidad de $100 \mathrm{~mL} /$ minuto $(19,20)$.

Microscopía electrónica de barrido (SEM): las películas se rasgaron con el fin de obtener vistas laterales y superficiales de la película. Las muestras fueron fotografiadas en un microscopio electrónico de barrido marca FEI QUANTA 200, en modo de alto vacío. Previamente las muestras fueron metalizadas en un spulter SDC-050 marca Balzers, en vacío intermedio menor a 10,2 torr, con argón como gas de ataque, sobre una placa de oro-paladio (8:1 ánodo). Las fotografías se tomaron en magnificación de $1000 \mathrm{x}$.

Microscopia óptica: se utilizó un estereomicroscopio Nikon, modelo SMZ800, con un objetivo de 1,5 y 6.3 x con luz reflejada y transmitida.

Pruebas realizadas a las frutas: a cada uno de los lotes se les realizó un seguimiento de las características visuales, de pérdida de peso, firmeza, sólidos solubles, pH y acidez titulable desde el día 3 al 6 para las fresas almacenadas a temperatura ambiente y del día 3 al 10 para aquellas almacenadas en refrigeración. El análisis sensorial se llevó a cabo en los días 3, 5 y 9. (Día 0 corresponde al día de cosecha de las frutas y el día 1 tiempo en el cual se aplicó el recubrimiento).

Pérdida de peso: se tomaron 6 fresas al azar por cada lote, que fueron pesadas en una balanza analítica Mettler Toledo AB204-S con una precisión de 0,0001g todos los días durante el tiempo de estudio, tres días a temperatura ambiente y siete días a temperatura de refrigeración.

Firmeza: se eligieron al azar tres fresas de cada lote y cada una de ellas se dispuso para que la perforación se diera en su zona ecuatorial en tres puntos diferentes. Esta medida se tomó mediante el uso de un texturómetro modelo TA TX PLUS utilizando el cilindro $(\mathrm{P} / 2)$. La medida obtenida indica la fuerza necesaria para penetrar la fruta $6 \mathrm{~mm}$ en función del tiempo o la distancia a una velocidad de $1 \mathrm{~mm} / \mathrm{s}$. La medida máxima registrada se expresó como la firmeza del pericarpio y el promedio de las medidas al final de la curva como la firmeza del mesocarpio.

Sólidos solubles totales (SST): para establecer el valor de SST como ${ }^{\circ}$ Brix se extrajo el jugo de la fruta en forma manual, del cual se tomó una gota para efectuar las mediciones con el refractómetro (21), realizando tres repeticiones de la medida, con tres fresas diferentes elegidas al azar.

pH: se tomó una alícuota de cada uno de los jugos elaborados para valorar SST y por cada lote se realizaron tres mediciones mediante un $\mathrm{pH}$-metro ORION 3-Star previamente calibrado.

Acidez titulable: se tituló una alícuota del jugo previamente elaborado para la determinación de sólidos solubles potenciométricamente con $\mathrm{NaOH}$ estandarizado (según la Norma Técnica Colombiana NTC 4103, frutas frescas. Fresa variedad Chandler).

Índice de madurez (IM): se calculó como el cociente entre los sólidos solubles y la acidez según NTC 4103.

Análisis sensorial: con el fin de encontrar la descripción sensorial de las fresas tratadas se realizó una prueba descriptiva cuantitativa. Cada panelista recibió una fresa por cada lote y un formato con una escala de 1 a 10 puntos para describir las características de brillo, aroma, sabor y textura y de 1 a 7 puntos para color (18). El panel estuvo constituido por 7 jueces entrenados del departamento de Química de la Universidad Nacional de Colombia, sede Bogotá. Las pruebas se realizaron los días 3 y 5 para las fresas almacenadas a temperatura ambiente y 3,5 y 9 para las fresas almacenadas en refrigeración. Se utilizó la prueba de Kruskal-Wallis para saber si existen diferencias en los parámetros sensoriales entre las fresas con diferentes tipos de recubrimiento y la prueba de Friedman para determinar si existen diferencias con cada tipo de recubrimiento y cada parámetro sensorial a través del tiempo (22).

Análisis estadístico: con el fin de observar la importancia estadística de cada uno de los factores de estudio se realizó un análisis multifactorial de varianza 
para cada característica evaluada Tipo III mediante el paquete estadístico de STATGRAPHYCS. Las gráficas realizadas para cada una de las pruebas fisicoquímicas presentan las medias con los intervalos LSD (mínima diferencia significativa) obtenidas para cada una de las características y factores a un nivel de confianza del $95.0 \%$. Para encontrar las medias que son significativamente unas de otras se utilizó el método HSD de Tukey (22).

\section{Resultados}

Respecto a la apariencia física y facilidad para desmoldar las películas formadas se observaron diferencias, aquellas que contenían únicamente almidón fueron mucho más blancas y más frágiles en comparación con las de proteína. En la Tabla 1 se muestra la influencia de la proteína y el aceite en la fuerza de tensión aplicada a las películas para ocasionar la ruptura en el eje ecuatorial de ellas.

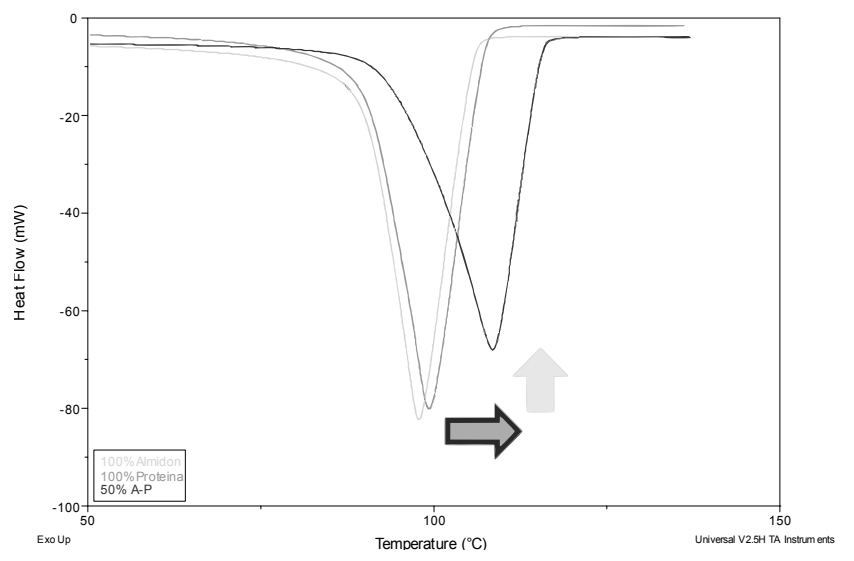

Tabla 1. Medidas de Tensión para las películas elaboradas.

\begin{tabular}{|cc|}
\hline Película & Fuerza (Newton) \\
\hline $100 \%$ Almidón & $0.3053( \pm 0.10)$ \\
\hline$(50: 50)$ Almidón- Proteína & $0.3404( \pm 0.11)$ \\
$(50: 50)$ A- P Sin Aceite & $0.6665( \pm 0.16)$ \\
$100 \%$ Proteína & $0.6500( \pm 0.07)$ \\
\hline
\end{tabular}

\section{Calorimetría diferencial de barrido modulado MDSC}

Los termogramas obtenidos muestran que sí hubo interacción entre el almidón y la proteína (Figura 1.a), la cual se manifiesta en el incremento de la temperatura de transición térmica para la mezcla comparada con el de los componentes puros y con la disminución del flujo de calor necesario para que se lleve a cabo el proceso cuando se encuentran estos dos hidrocoloides. Las figuras $1 \mathrm{~b}$ y $1 \mathrm{c}$, muestran cada uno de los componentes del flujo total de calor, calor reversibles y no reversible respectivamente. En

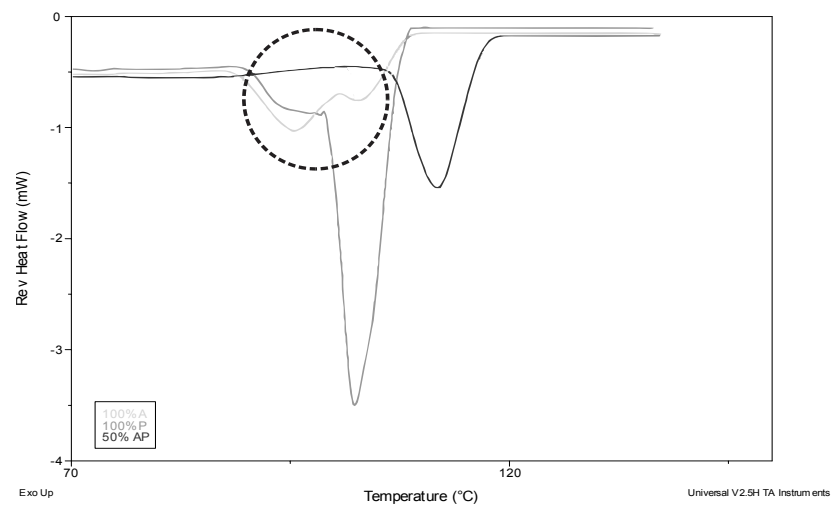

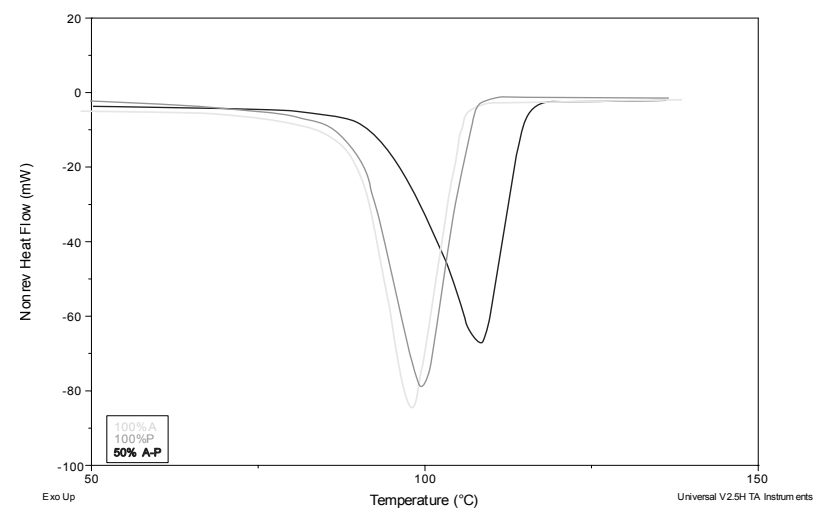

Figura 1. Termograma MDSC (a) Flujo de calor total (b) Flujo de calor reversible (c) Flujo de calor irreversible. 


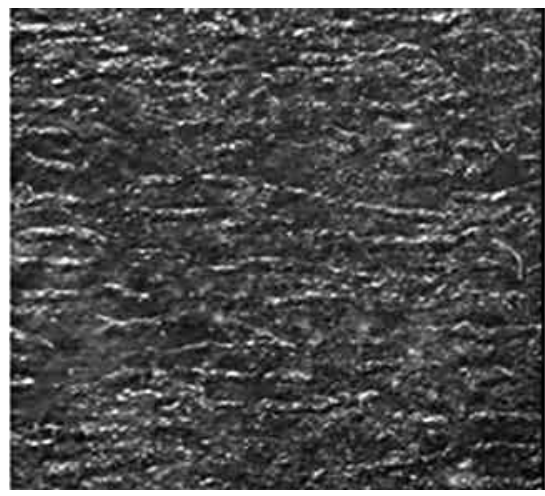

(a)

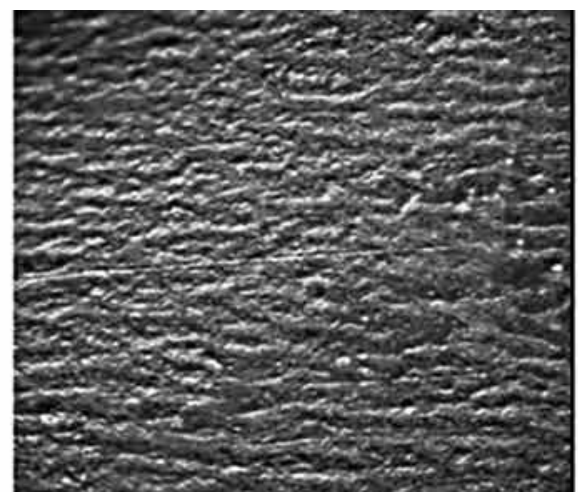

(b)

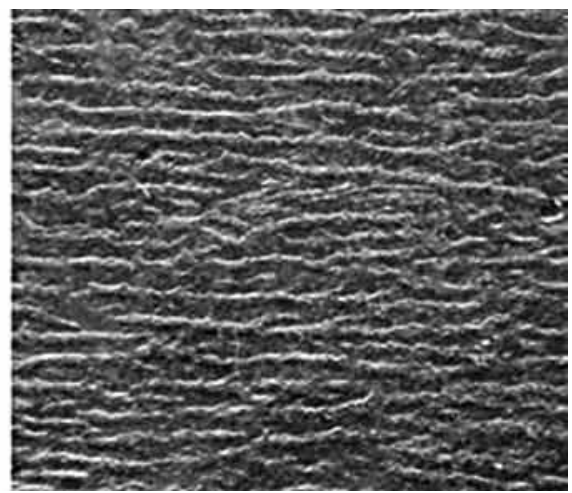

(c)

Figura 2. Microscopia óptica para las películas de (a) Almidón (b) Almidón: Proteína 50:50 (c) Proteína.

la Figura $1 \mathrm{~b}$ se observa un evento térmico similar a una transición vítrea previo a la gelatinización del almidón y a la desnaturalización de la estructura de la proteína, que desaparece en la mezcla de componentes.

\section{Microscopía óptica y electrónica de barrido (SEM)}

La morfología de las películas se observan en las figuras 2 y 3. En las imágenes correspondientes a la microscopía óptica, para la película de proteína, se observa una estructura mucho más homogénea en comparación con las películas que contienen almidón. Las imágenes correspondientes a la microscopía electrónica de barrido muestran una pérdida de las estructuras típicas de la materia prima, Figura 4, dando origen a la formación de un material más continuo y con mayor compactación, Figura 3a y 3b.

\section{Evaluación de las películas sobre fresas}

Seguimiento visual. La aplicación de los recubrimientos sobre las fresas y la temperatura de refrigeración en el almacenamiento presentaron un efecto benéfico en la apariencia, prolongando su buen aspecto físico durante el almacenamiento. Las fresas almacenadas a temperatura ambiente presentaron daños microbiológicos por el hongo Botritys cinerea (moho gris) entre el día 6-7 (razón por la cual los análisis se realizaron sólo hasta el día 6 , en aquellas que se encontraran libres de este ataque microbiológico). Las fresas almacenadas a $7^{\circ} \mathrm{C}$ no presentaron la patología mencionada. En cuanto a la naturaleza de los recubrimientos la inclusión de proteína permitió mantener la apariencia de las frutas durante su almacenamiento.

Pérdida de peso. El tratamiento estadístico realizado a los datos indicó que hay diferencias significativas en la pérdida de peso para cada uno de los factores evaluados: tiempo, recubrimiento y temperatura de almacenamiento. En todas las formulaciones que incluían proteína se observó un efecto positivo, disminuyendo el porcentaje de pérdida de peso comparado con las fresas patrón, Tabla 2. El recubrimiento que presentó mayor protección para la pérdida de peso fue el que contenía únicamente como material hidrocoloide la proteína aislada de soya. A diferencia de este, el recubrimiento elaborado con almidón presentó un efecto negativo incrementando la pérdida de peso del fruto durante su almacenamiento.

$\mathrm{Al}$ analizar la naturaleza y propiedades de estas dos macromoléculas y su interacción con el componente lipídico de los recubrimientos puede explicarse por qué el recubrimiento de proteína presentó la mejor opción para disminuir la pérdida de peso. La proteína de soya debido a su carácter anfifílico y emulgente produjo una película más resistente a la difusión del agua originando una mejor barrera de protección evitando así la deshidratación.

En los recubrimientos que contenían proteína se observa que la pérdida de peso es mayor cuando las fresas no se almacenan en temperaturas de refrigeración, ya que en esta temperatura se logra disminuir los procesos metabólicos y de respiración, Tabla 3. 

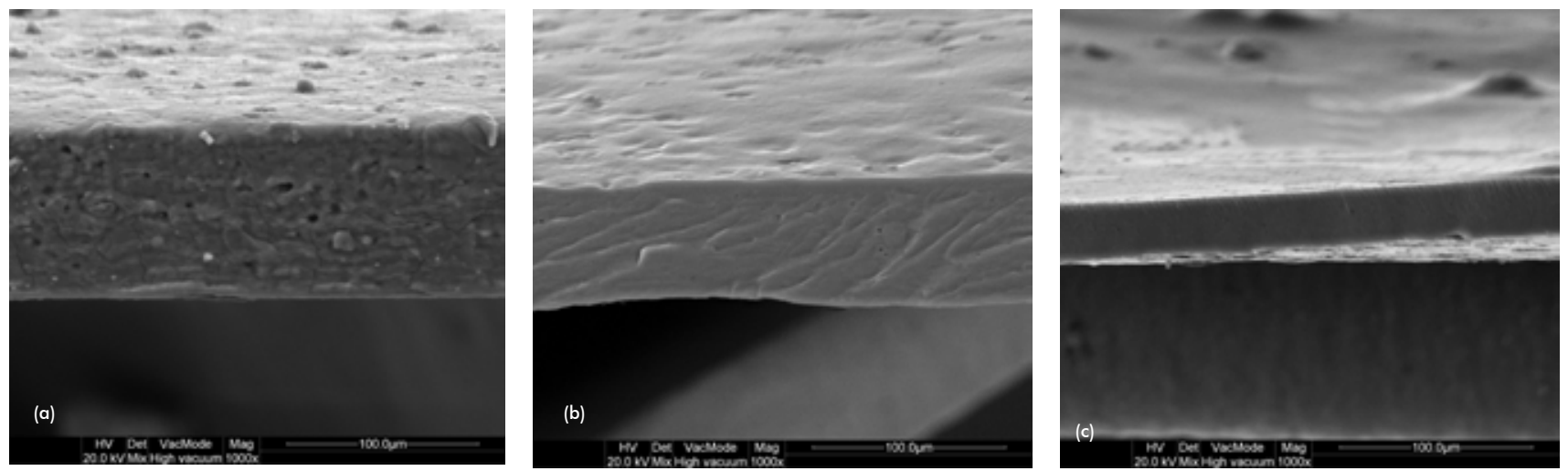

Figura 3. SEM para las películas de (a) Almidón (b) Almidón-Proteína 50:50 (c) Proteína.

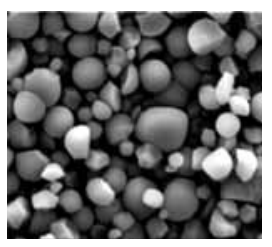

Figura 4. Imagen SEM de la estructura granular del almidón nativo.
Firmeza. Los resultados obtenidos no mostraron cambios estadísticamente significativos ( $p>0.05)$ en la firmeza del fruto del pericarpio y mesocarpio de las fresas recubiertas durante su almacenamiento en las dos temperaturas de evaluación.
Sólidos solubles totales. La aplicación de los recubrimientos en las fresas no generó diferencias significativas en el contenido de sólidos solubles totales entre los tratamientos evaluados durante el almacenamiento ( $p>0.05$ ), este comportamiento es de esperarse debido a que la fresa pertenece a las frutas no climatéricas.

Tabla 2. Influencia del recubrimiento en la pérdida de peso al final de la vida útil.

\begin{tabular}{|c|c|c|c|}
\hline $\begin{array}{l}\text { Recubrimiento } \\
\text { (Temp } 18^{\circ} \mathrm{C} \text { ) }\end{array}$ & $\%$ Pérdida de Peso* & $\begin{array}{c}\text { Recubrimiento } \\
\left.\text { (Temp } 7{ }^{\circ} \mathrm{C}\right)\end{array}$ & $\%$ Pérdida de Peso* \\
\hline 100 \% Almidón & $\begin{array}{c}(-) 3.18 \% \\
( \pm 0.01)\end{array}$ & Almidón & $\begin{array}{c}(-) 4.49 \% \\
( \pm 0.01)\end{array}$ \\
\hline Almidón-Proteína (50:50) & $\begin{array}{c}(+) 0.10 \% \\
( \pm 0.01)\end{array}$ & Almidón-Proteína (50:50) & $\begin{array}{c}(+) 0.31 \% \\
( \pm 0.01)\end{array}$ \\
\hline 100\% Proteína & $\begin{array}{c}(+) 3.15 \% \\
( \pm 0.01)\end{array}$ & Proteína & $\begin{array}{c}(+) 1.88 \% \\
( \pm 0.01)\end{array}$ \\
\hline
\end{tabular}

*. El signo (-) o (+) indica el efecto negativo o positivo que brindó el recubrimiento según haya aumentando o disminuido la pérdida de peso del fruto respectivamente. Todos los porcentajes se determinaron tomando como base la pérdida obtenida para las fresas sin recubrimiento (fresas patrón) a las dos temperaturas de almacenamiento: ambiente $\left(18^{\circ} \mathrm{C}\right)$ entre los días $3-5$ y de refrigeración $\left(7^{\circ} \mathrm{C}\right)$ entre los días 3 y 7.

Tabla 3. Influencia de la temperatura de almacenamiento durante lo dos primeros días de almacenamiento.

\begin{tabular}{|c|c|c|c|}
\hline Fruta Evaluada & $\begin{array}{l}\text { \% Pérdida de Peso* } \\
\text { (Temp } 18^{\circ} \mathrm{C} \text { ) }\end{array}$ & Fruta Evaluada & $\begin{array}{l}\text { \% Pérdida de Peso* } \\
\text { (Temp } 7^{\circ} \mathrm{C} \text { ) }\end{array}$ \\
\hline Fresas Patrón & $5.67 \%( \pm 0.01)$ & Fresas Patrón & $1.87 \%( \pm 0.01)$ \\
\hline Fresas $-100 \%$ Almidón & $6.72 \%( \pm 0.01)$ & Fresas - 100 \% Almidón & $7.15( \pm 0.01)$ \\
\hline $\begin{array}{l}\text { Fresas - } \\
\text { A-P }(50: 50)\end{array}$ & $5.47( \pm 0.01)$ & $\begin{array}{l}\text { Fresas - } \\
\text { A-P (50:50) }\end{array}$ & $2.31( \pm 0.01)$ \\
\hline Fresas $-100 \%$ Proteína & $5.33( \pm 0.01)$ & Fresas $-100 \%$ Proteína & $1.72( \pm 0.01)$ \\
\hline
\end{tabular}

* Tomando como base el peso determinado el día 3. 

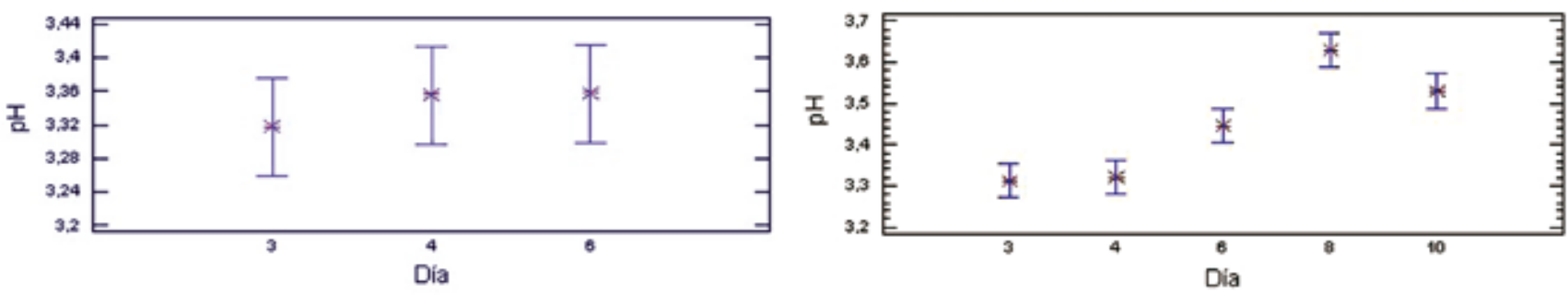

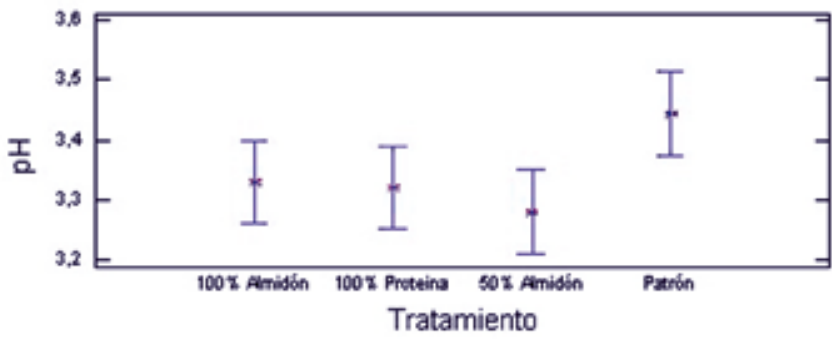

a)

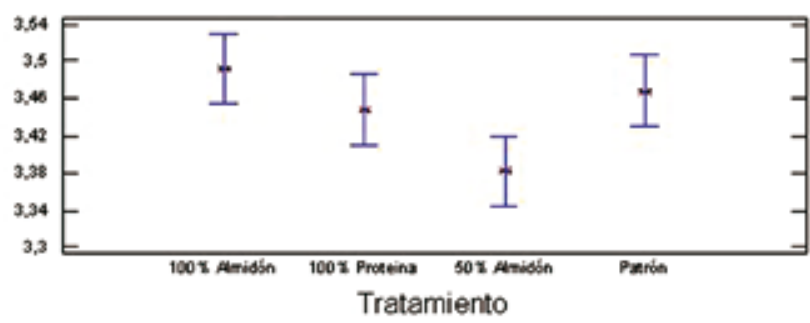

b)

Figura 5. Determinación de firmeza en el pericarcarpio (a) Temperatura ambiente (b).

pH. La variación de esta propiedad resultó significativa para la temperatura de refrigeración, la tendencia mostrada en la Figura $5 \mathrm{~b}$ puede ser consecuencia del stress al cual se somete el fruto, ya que una vez arrancado de la planta durante los primeros días se ve obligado a gastar parte de sus ácidos orgánicos como parte de sus procesos metabólicos. La disminución que se observa al final puede ser ocasionada por la presencia de microorganismos, sin embargo debido a que no se realizaron otras pruebas no es posible asegurar alguna de las hipótesis mencionadas.

Acidez titulable. Para los diferentes recubrimientos no se encontraron diferencias significativas, pero sí para las variaciones de la propiedad durante el tiempo, Figura 6. Hasta el día 6 se observa una ligera variación, que luego tiende a su estabilización y puede ser ocasionada por el stress al cual se ve sometido el fruto una vez cosechado y puesto el recubrimiento sobre él. Para los recubrimientos utilizados no se observaron efectos significativos.

Índice de madurez. Los sólidos solubles no variaron al prolongar el almacenamiento, pero debido a la variación obtenida para el día 4 en acidez, el índice de madurez cambia significativamente, aunque no es lo esperado, ya que la fresa es un fruto no climatérico y se esperaría que este factor no varíe en función del tiempo durante el almacenamiento. Para los recubrimientos utilizados no se encontró un efecto significativo.

Análisis sensorial. Los resultados de la prueba de Kruskal-Wallis para determinar si existían diferencias en cada uno de los parámetros sensoriales en las fresas con diferente tipo de recubrimiento y de almacenamiento se muestran en la Tabla 4, en la cual se observa que no existe una evidencia estadística para rechazar la hipótesis nula, es decir, no hay diferencias entre los tipos de fresas, para ninguno de los parámetros sensoriales, en ninguno de los tiempos de almacenamiento.

En la Tabla 5 se encuentran los resultados de la prueba de Friedman que se realizó para determinar si existían cambios para cada tipo de fresa y cada parámetro sensorial, durante el tiempo del ensayo. También se encuentra que para las fresas almacenadas a temperatura ambiente las únicas que presentaron cambios significativos durante la prueba fueron las fresas patrón. Las fresas almacenadas a temperatura de refrigeración en el recubrimiento de proteína no presentaron diferencias significativas. Comparando ambas temperaturas de almacenamiento se observa que el atributo sensorial más afectado fue el de aroma y sabor.

Con el propósito de encontrar el tiempo en el cual se presentó dicha diferencia se realizaron pruebas de 

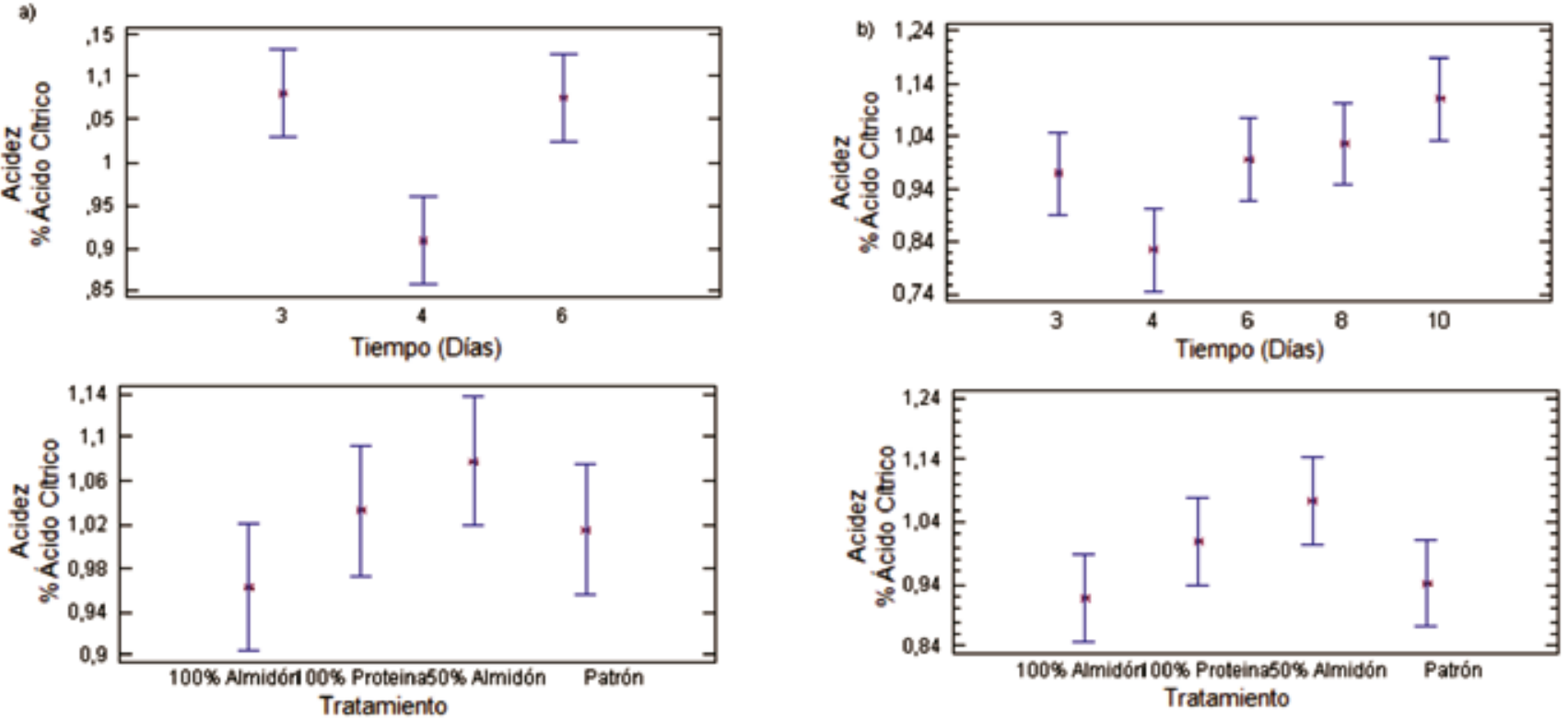

a)

b)

Figura 6. Determinación de acidez titulable (\%acido cítrico) (a) Temperatura ambiente (b) Temperatura de refrigeración.

Tabla 4. Valores p para las pruebas de Kruskal-Wallis

\begin{tabular}{|c|ccc|}
\hline Parámetro & \multicolumn{3}{c|}{ Tiempos } \\
\hline Sensorial & Tiempo 1 & Tiempo 2 & Tiempo 3 \\
\hline Apariencia y Brillo & 0.11 & 0.27 & 0.80 \\
\hline Aroma y Sabor & 0.17 & 0.78 & 0.90 \\
Color & 0.17 & 0.48 & 0.84 \\
\hline Textura & 0.43 & 0.63 & 0.43 \\
\hline
\end{tabular}

Tabla 5. Valores p para la prueba de Friedman.

\begin{tabular}{|c|c|c|c|c|}
\hline \multirow{2}{*}{ Tipos de Fresas } & \multicolumn{4}{|c|}{ Parámetros Sensoriales } \\
\hline & Apariencia y brillo & Aroma y sabor & Color & Textura \\
\hline Patrón ambiente & 0.70 & 0.01 & 0.26 & 0.01 \\
\hline $\begin{array}{l}100 \% \text { Almidón } \\
\text { Ambiente }\end{array}$ & 1.00 & 0.10 & 0.06 & 0.10 \\
\hline (50:50) A-P Ambiente & 0.65 & 0.41 & 0.10 & 0.06 \\
\hline $\begin{array}{l}\text { 100\% Proteína } \\
\text { Ambiente }\end{array}$ & 0.41 & 0.26 & 0.10 & 0.08 \\
\hline Patrón Nevera & 0.03 & 0.61 & 0.07 & 0.09 \\
\hline $100 \%$ Almidón Nevera & 0.07 & 0.01 & 0.02 & 0.12 \\
\hline (50:50) A-P Nevera & 0.14 & 0.01 & 0.70 & 0.09 \\
\hline 100\% Proteína Nevera & 0.15 & 0.11 & 0.95 & 0.13 \\
\hline
\end{tabular}


Tabla 6 Tabla de comparaciones Múltiples para las muestras de Friedman con valor $\mathrm{p}<0.05$.

\begin{tabular}{|ccccc}
\hline Contraste & Patrón Nevera & $\begin{array}{c}100 \% \text { Almidón } \\
\text { Nevera }\end{array}$ & $\begin{array}{c}100 \% \text { Almidón } \\
\text { Nevera }\end{array}$ & $\begin{array}{c}50: 50 \\
\text { A-P Nevera }\end{array}$ \\
\hline $\mathrm{t}_{1}-\mathrm{t}_{2}$ & (Apariencia y brillo) & (Aroma y Sabor) & (Color) & (Aroma y Sabor) \\
\hline $\mathrm{t}_{1}-\mathrm{t}_{3}$ & 2.5 & ${ }_{-}-7.5$ & -4 & ${ }_{-}-9.0$ \\
$\mathrm{t}_{2}-\mathrm{t}_{3}$ & -5.5 & ${ }^{*}-9.0$ & ${ }^{*}-8$ & ${ }_{-}-7.5$ \\
& $*-8.0$ & -1.5 & -4 & 1.5 \\
\hline
\end{tabular}

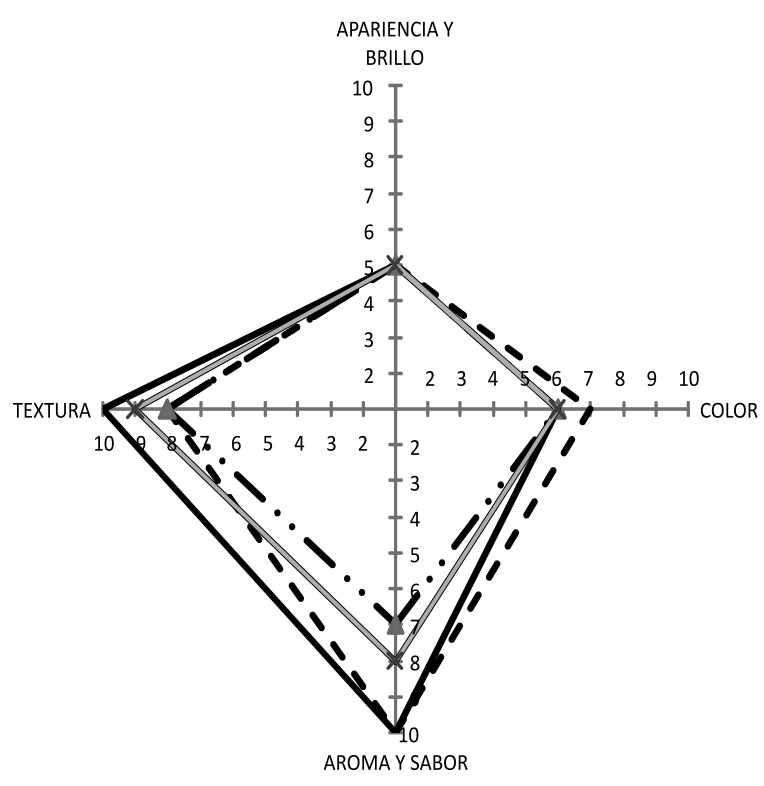

a)

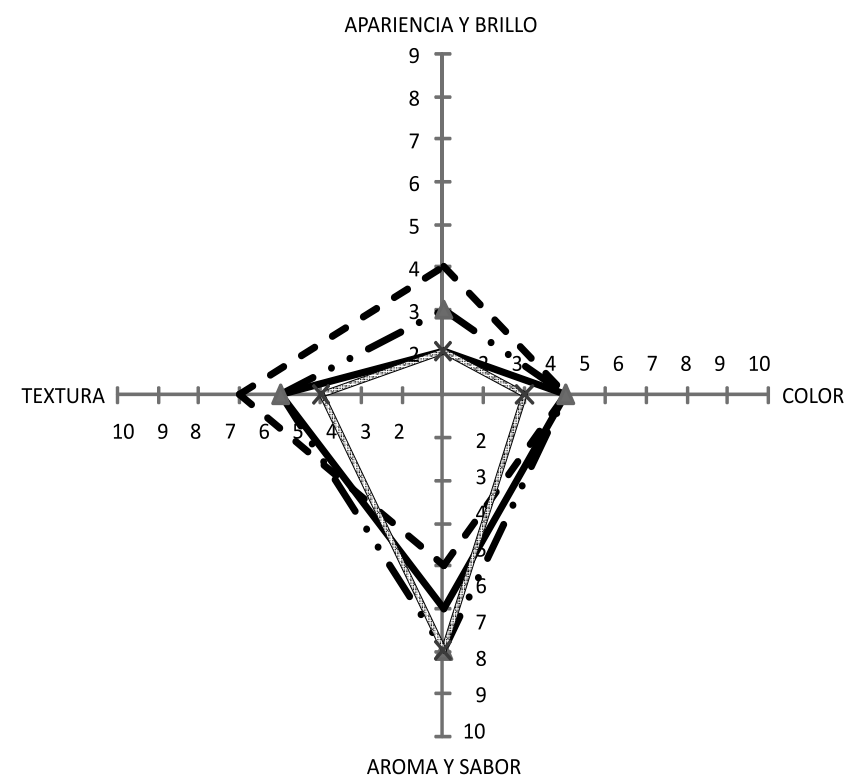

b)

Figura 7. Perfiles sensoriales para las fresas almacenadas a temperatura ambiente. (a) Primera sesión: día 3 (b) Segunda sesión: día 5.

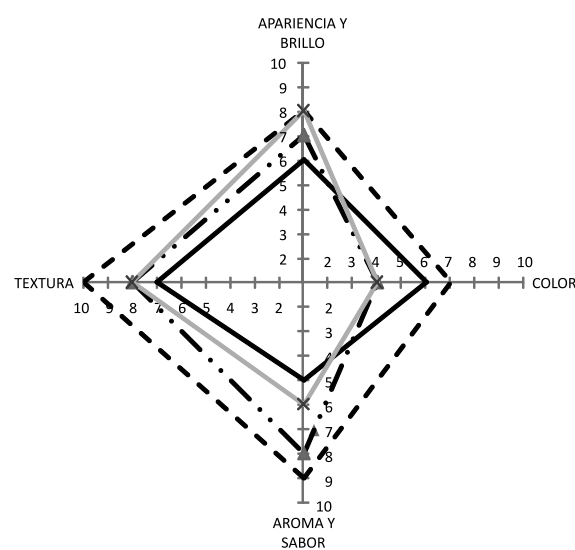

a)

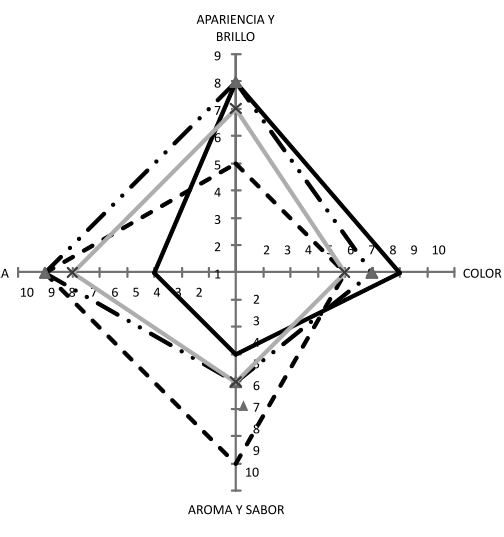

b)

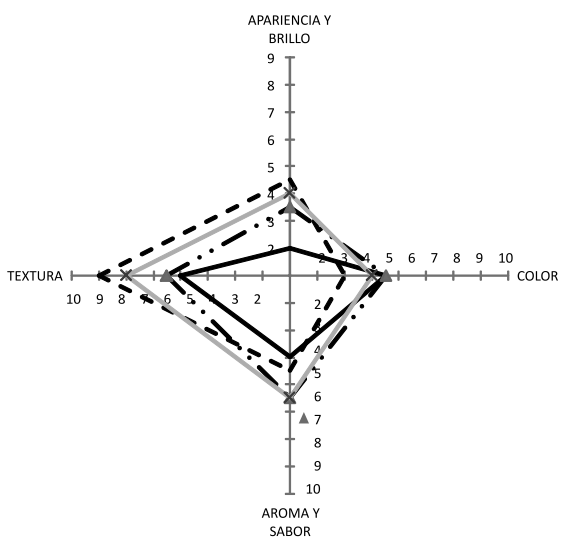

c)

Patrón — Almidón — - - 50\% A-P — - Proteína

Figura 8. Perfiles sensoriales para las fresas almacenadas en refrigeración. (a) Primera sesión: día 3(b) Segunda sesión: día 5 (c) Tercera sesión: día 9.

comparación múltiple para cada caso, (exceptuando el tratamiento de temperatura ambiente, en el que sólo se tuvieron dos tiempos por lo cual la diferencia encontrada estaría dentro de ese intervalo) cuyos resultados muestran que la mayoría de diferencias se encontraron entre el tiempo 1 y el tiempo 3, Tabla 6 . 
En las figuras 7 y 8 se muestran los perfiles sensoriales para cada sesión realizada. Comparando ambas figuras se observa que para la misma sesión se obtuvieron valores más altos en las fresas almacenadas a la temperatura de refrigeración y que al aumentar el tiempo de almacenamiento se obtiene una disminución de los atributos.

\section{Discusión}

La incorporación de proteína de soya permitió que las películas tuvieran un secado más homogéneo, una mayor elasticidad y facilidad para despegarlas del molde. La proteína aumentó la resistencia de la película, mientras que el aceite la debilitó, lo cual puede ser explicado al considerar que la proteína de soya al estar a un $\mathrm{pH}$ por arriba de su punto isoeléctrico, tiene una carga neta negativa con lo cual podría presentar formación de enlaces disulfuro. El efecto del aceite se puede considerar al tener en cuenta que por la naturaleza de la proteína interaccionaría con ella por medio de enlaces hidrofóbicos debilitando así las fuerzas existentes entre la proteína y el almidón que corresponden a interacciones mucho más fuertes tipo puentes de hidrógeno. Los análisis de calorimetría diferencial de barrido permiten evidenciar interacción y efecto de la mezcla de almidón y proteína.

La aplicación de las películas de almidón donde se incorporó proteína de soya evidencian un buen desempeño desde el punto de vista fisicoquímico y sensorial sobre las fresas puestas a prueba, esto debido a una mejora en las capacidades filmogénicas, como resultado de la interacción entre las macromoléculas que favorece una disminución en la pérdida de humedad, buena calidad sensorial y el mantenimiento de otros parámetros de calidad de la fruta en buenas condiciones.

Finalmente, al comparar los resultados obtenidos del presente estudio con el uso exclusivo de almidón de yuca como macromolécula con capacidad filmogénica en el recubrimiento (18) se observó que la inclusión de proteína mejoró el desempeño de este como medio de conservación de las características del fruto, determinados en la disminución de la pérdida de peso y en los atributos sensoriales durante el tiempo de almacenamiento.

La realización de este trabajo permitió establecer que la inclusión de la proteína aislada de soya en la formulación de las películas comestibles mostró una interacción con el almidón mejorando sus propiedades mecánicas y su desempeño como recubrimiento sobre las fresas. Además, los recubrimientos comestibles no presentaron diferencias significativas en las propiedades sensoriales en cuanto al tipo de tratamiento, pero sí un efecto positivo a través del tiempo. Las únicas propiedades fisicoquímicas evaluadas en fresas que presentaron diferencias significativas entre los tratamientos utilizados fueron la pérdida de peso y el pH. Propiedades de SST, firmeza, acidez titulable no presentaron cambios significativos.

\section{Referencias}

1. Navarros T. M., Efecto de la composición de recubrimientos comestibles a base de hidroxiplimetilcelulosa y cera de abeja en la calidad de ciruelas, mandarinas y milojas. Universidad Politécnica de Valencia. Departamento de tecnología de alimentos, 2007.

2. Tanada S.P, Grosso C., Effect of edible wheat gluten-based films and coatings on refrigerated strawberry (Fragaria anassa quaility) Postharvest Biology and Technology. 36,199-208, 2005.

3. Cisneros Z, Krochta L., Internal modified atmospheres of coated fresh fruits and vegetables: understanding relative humidity effects. J.Food Sci, 67 (8):2792-2797, 2002.

4. Ribeiro C., Vicente A., Teixeira J.,Miranda C., Optimization of edible coating composition to retard strawberry fruit senescence. Postharvest Biology and Technology. 44,63-70, 2007.

5. Vargas M., Albors A., Chiralt A., González C., Quality of cold -stored strawberries as affected by chitosan-oleic acid edible coatings. Postharvest Biology and Technology 41, 164-171, 2006.

6. Bermúdez S., Rozo P., Preparación de películas para alimentos a partir de concentrados proteicos de haba (Vicia faba).Revista colombiana de química. 32, 1, 2003.

7. Nisperos C, M., Edible coatings and films based on polysaccharides. Protein-based films and coatings. Eds.J.M Krochta; E.A.Baldwin, M.O. Technomic Publishing Co.,Inc Lancaster, U.S.A., pp 305-335, 1994.

8. Aguilar M. M, Propiedades físicas y mecánicas de películas biodegradables y su empleo en el recubrimiento de frutos de aguacate. Centro de investigación en ciencia aplicada y tecnología avanzada. Instituto Politécnico Nacional. México D.F pp 24-38, 2005.

9. Tharanathan R. N, Biodegradable films and composite coatings: past, present and future. Trends in food science and Technology. 14, 71-78, 2003.

10. Doublier J.L., Garnier C., Renard D., Protein -polysaccharide interactions. Current Opinion in Colloid \& Interface Science. 5, 202-214, 2000.

11. Jeng Y., Yeh A., Fan K., Gelation characteristics and morphology of corn starch/soy protein concentrate composites during heating, Journal of food engineering. $78,1240-1247,2007$. 
12. Parra D. F., Tadini C.C., Ponce P., Lugão A.B. Mechanical properties and water vapor transmission in some blends of cassava starch edible films . Carbohydrate Polymers. 58 , 475-481, 2004.

13. Cho S.,Rhee C., Mechanical properties and water vapor permeability of edible films made from fractionated soy proteins with ultrafiltration Lebensmittel Wissenchaft und Technologie. 37, 833-839, 2004.

14. Rhim J-W., Gennadios A., Weller C., Cezeirat C., Hanna M., Soy protein isolate-dialdehyde starch films. Industrial Crops and Products 8, 195-203, 1998.

15. Kumar R., Zhang L., Soy protein films with the hydrophobic surface created through non-covalent interactions. Industrial Crops and products. 29, 485-494, 2009.

16. Almenar R. E., Envasado Activo de Fresas Silvestres, Facultad de Farmacia, Instituto de Agroquímica y Tecnología de Alimentos, 2005.

17. Han C., Zhao Y.,Traber M.G., Edible coatings to improve storability and enhance nutritional value of fresh and frozen strawberries
(Fragraria $\mathrm{x}$ ananassa) and raspberries (Rubus ideaus) Postharvest Biology and Techonogy. 33, 67-78, 2004.

18. Cardona J., Desarrollo de una película para la conservación de fresas, Universidad Nacional de Colombia, Bogotá, 2007.

19. Aldana A., Sandovla E., Quintero A., Aplicación del análisis por calorimetría diferencial de barrido (DSC) por la caracterización de las modificaciones del almidón. Dyna, 72,146 pp 45-53, 2005.

20. Meuter De P., Rahier H., Van M B.,The use of modulates temperature differential scanning calorimetry for the characterisation of food systems. International Journal of Pharmaceutics. 192,77-84, 1999.

21. Alarcón, Robayo A,. Desarrollo de una cubierta comestible para la conservación de productos vegetales perecederos. Universidad Nacional de Colombia, Bogotá, 2004.

22. Conover, W.J., Practical nonparametric statistics, wiley series in probability and statistics west Sussex, Reino Unido, 1998. 